\title{
Correction to: Classes of tree-based networks
}

Mareike Fischer $^{1 *}$, Lina Herbst ${ }^{1}$, Michelle Galla ${ }^{1}$, Yangjing Long ${ }^{2}$ and Kristina Wicke ${ }^{1}$

\section{Correction to: Vis Comput Ind Biomed Art 3, 12} (2020)

https://doi.org/10.1186/s42492-020-00043-z

Following publication of the original article [1], in the description of the leaf shrinking procedure as well as in Algorithm 1 and the definition of edge-based graphs in [1], the condition that $G$ contains at least two leaves (i.e., the condition $\left|V_{L}(G)\right| \geq 2$ ) needs to be omitted. Moreover, in line 2 of Algorithm 1 it should read $|V(\mathcal{L} S(G))|>2$.

In particular, Algorithm 1 and Definition 3 should read as follows:
The original article can be found online at https://doi.org/10.1186/s42492020-00043-z.

* Correspondence: email@mareikefischer.de

${ }^{1}$ Institute of Mathematics and Computer Science, University of Greifswald Greifswald, Germany

Full list of author information is available at the end of the article

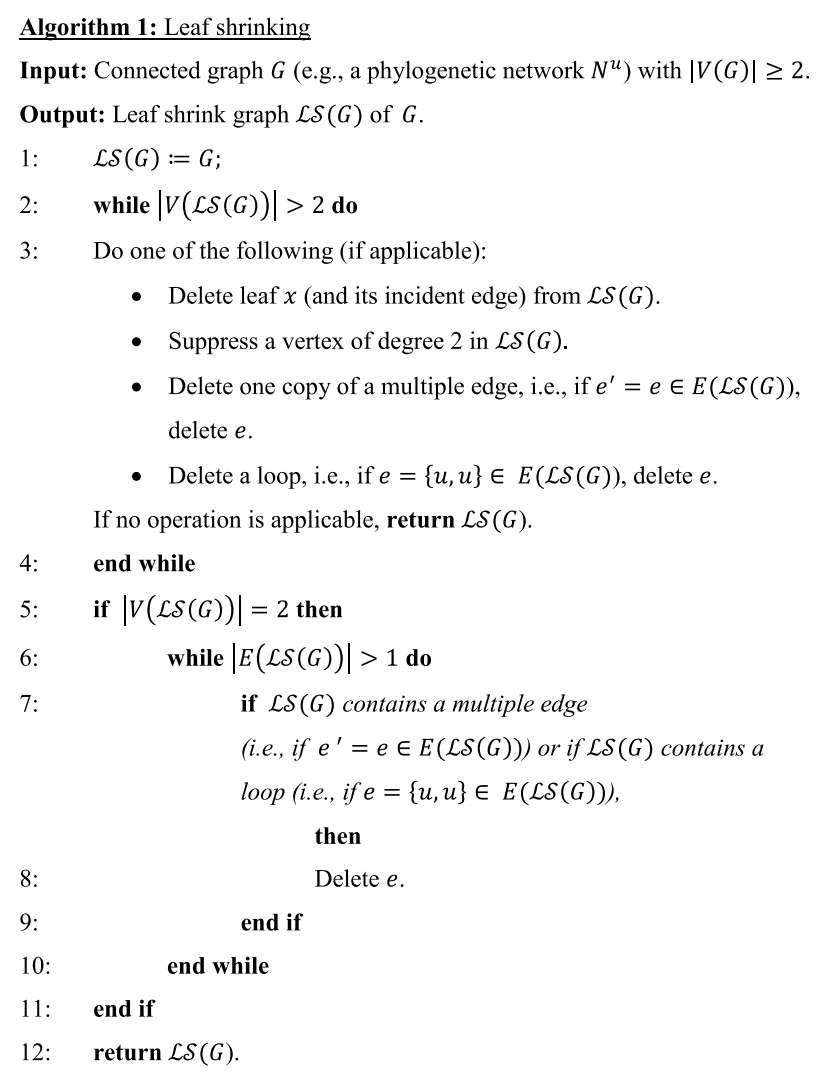

Definition 3 Let $G$ be a connected graph with $|V(G)| \geq$ 2. If the leaf shrink graph $\mathcal{L} S(G)$ of $G$ is a single edge, $G$ is called edge-based. Else, $G$ is called non-edge-based. If $G=N^{u}$ is a proper phylogenetic network with $\left|V\left(N^{u}\right)\right| \geq$ 2 and $|X| \geq 2$ and $\mathcal{L} S\left(N^{u}\right)$ is a single edge, we call $N^{u}$ an edge-based network. Else, $N^{u}$ is called non-edge-based.

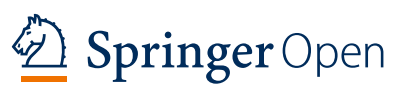

(c) The Author(s). 2021 Open Access This article is licensed under a Creative Commons Attribution 4.0 International License, which permits use, sharing, adaptation, distribution and reproduction in any medium or format, as long as you give appropriate credit to the original author(s) and the source, provide a link to the Creative Commons licence, and indicate if changes were made. The images or other third party material in this article are included in the article's Creative Commons licence, unless indicated otherwise in a credit line to the material. If material is not included in the article's Creative Commons licence and your intended use is not permitted by statutory regulation or exceeds the permitted use, you will need to obtain permission directly from the copyright holder. To view a copy of this licence, visit http://creativecommons.org/licenses/by/4.0/. 
We thank Tom Niklas Hamann for bringing this issue to our attention.

\section{Author details}

${ }^{1}$ Institute of Mathematics and Computer Science, University of Greifswald, Greifswald, Germany. ${ }^{2}$ School of Mathematics and Statistics, Central China Normal University, Wuhan, Hubei, China.

Published online: 26 January 2021

\section{Reference}

1. Fischer M, Herbst L, Galla M, Long Y, Wicke K (2020) Classes of tree-based networks. Vis Comput Ind Biomed Art 3:12 